\title{
Inovasi desain dan simulasi model prostesis bawah lutut berdasarkan antropometri orang indonesia
}

\author{
Donny Suryawan', Muhammad Ridlwan², Ari Setiadi \\ ${ }^{1}$ Departemen Teknik Mesin, Fakultas Teknologi \\ Industri, Universitas Islam Indonesia \\ Jl. Kaliurang km 14,5, Ngemplak, Sleman, \\ Yogyakarta 55583, \\ Email korespondensi: donny.suryawan@uii.ac.id
}

\begin{abstract}
Abstrak
Data kesehatan tahun 2012 menunjukkan bahwa 2,45 \% dari jumlah penduduk Indonesia merupakan penyandang disabilitas. Penderita tuna daksa menempati posisi kedua setelah gangguan pada penglihatan. Amputasi bawah lutut adalah salah satu bentuk tuna daksa yang banyak terjadi di Indonesia. Pasien amputasi bawah lutut akan kesulitan berjalan karena ketiadaan organ akibat amputasi. Prostesis bawah lutut merupakan alat pengganti organ bawah lutut. Prostesis bawah lutut akan membantu penderita amputasi bawah lutut agar dapat berdiri dan berjalan. Saat ini, produk prostesis bawah lutut yang ada di Indonesia masih memiliki banyak kekurangan. Pembuatan prostesis masih menggunakan metode custom sehingga membutuhkan proses pembuatan yang lama dan harga yang relatif mahal. Produksi massal tentu dapat menjadi solusi untuk menekan harga dan waktu pembuatan. Desain prostesis bawah lutut yang dapat mengakomodasi rentang antropometri orang Indonesia diperlukan agar prostesis bawah lutut dapat diproduksi secara massal. Hasil pembuatan desain kemudian diuji melalui simulasi sesuai standar ISO 10328 sebelum pembuatan prototipe dan produksi. Prostesis bawah lutut tersebut dirancang untuk mampu menahan beban $100 \mathrm{~kg}$ dengan safety factor 4. Selain itu, prostesis bawah lutut yang telah dirancang dapat digunakan untuk penderita yang memiliki rentang tinggi badan antara $150 \mathrm{~cm}$ hingga $180 \mathrm{~cm}$.
\end{abstract}

Kata kunci: desain, inovasi, prostesis.

\begin{abstract}
Health data in 2012 shows that $2.45 \%$ of Indonesia's population are people with disabilities. Sufferers of forced tuna are second only to impaired vision. Under-knee amputation is one form of a physical disability that is common in Indonesia. Under knee amputation, patients will have difficulty walking because of the absence of organs due to amputation. Under knee, the prosthesis is an organ replacement under the knee. Under-knee prostheses will help amputation sufferers under the knee to stand up and walk. At present, under-knee prosthesis products in Indonesia still have many disadvantages. The manufacture of prostheses still uses a custom method so that it requires a long manufacturing process and a relatively high price. Mass production can certainly be a solution to reduce the cost and time of manufacture. Under-knee prosthetic designs that can accommodate the anthropometric range of Indonesians are needed so that the under-knee prosthesis can be mass-produced. The results of the model are then tested through simulations according to the ISO 10328 standard before making prototypes and production. Under knee, the prosthesis is designed to be able to withstand a load of $100 \mathrm{~kg}$ with safety factor 4. Also, a prosthesis under the knee that has been developed can be used for patients who have a range of height between $150 \mathrm{~cm}$ to $180 \mathrm{~cm}$.
\end{abstract}

Keywords: design, innovation, prosthesis

\section{Pendahuluan}

Perkembangan dari tahun-ketahun menunjukkan bahwa penderita disabilitas terus mengalami peningkatan. Tahun 2012 Badan Pusat Statistik telah melakukan survei mengenai penderita cacat di Indonesia. Menurut pengamatan yang telah dilaksanakan terdapat 2,45\% dari keseluruhan jumlah penduduk Indonesia yang mengalami cacat, baik itu cacat mental maupun cacat fisik. Berdasarkan sensus yang dilaksanakan 2 tahun sebelumnya yaitu tahun 2010 diperoleh data bahwa terdapat sekitar 2432000 jiwa yang mengalami sedikit gangguan pada kemampuan berjalan atau naik tangga dan terdapat sekitar 656000 jiwa yang menderita gangguan pada kemampuan berjalan atau naik tangga yang dikategorikan dalam kondisi parah [1].

Amputasi bawah lutut adalah salah satu bentuk tuna daksa yang banyak terjadi di Indonesia. Pasien amputasi bawah lutut akan kesulitan berjalan karena ketiadaan organ akibat amputasi. Prostesis bawah lutut merupakan alat pengganti organ bawah lutut yang dapat membantu penderita amputasi bawah lutut agar dapat berdiri dan berjalan. Saat ini, produk prostesis bawah lutut yang ada di Indonesia masih 
memiliki banyak kekurangan. Pembuatan prostesis masih menggunakan metode custom sehingga membutuhkan proses pembuatan yang lama dan harga yang relatif mahal. Waktu tunggu produksi yang lama dapat mengakibatkan terkendalanya berbagai aktivitas keseharian dari penggunanya. Produksi massal tentu dapat menjadi solusi untuk menekan harga dan waktu pembuatan. Berdasarkan kekurangan produk tersebut dapat dipecahkan dengan cara merancang sebuah desain prostesis bawah lutut yang sesuai dengan antropometri orang Indonesia yaitu dengan ketinggian antara 150 hingga $180 \mathrm{~cm}$ dan dapat digunakan oleh beberapa orang dengan kondisi tertentu sehingga dapat diproduksi secara massal dan dapat menekan biaya produksinya. Prostesis ini diharapkan mampu menggantikan fungsi kaki sebagai mana mestinya dengan memperhatikan aspek antropometri orang Indonesia sesuai dengan Tabel 1.

Jenis prostesis seperti yang terlihat pada Gambar 1 sudah banyak dikembangkan, baik itu tanpa motor penggerak maupun menggunakan motor penggerak. Namun jenis motor penggerak yang digunakan hanya untuk menggerakan bagian ankle. Selain menggunakan motor jenis foot yang memiliki penyangga di bagian bawah akan mempengaruhi seseorang ketika berjalan. Bagian ini akan memberikan daya lenting kearah depan ketika digunakan [2].

Tabel 1. Antropometri orang Indonesia

\begin{tabular}{ccc}
\hline Kriteria & $\begin{array}{c}\text { Dimensi } \\
\text { Minimum }\end{array}$ & $\begin{array}{c}\text { Dimensi } \\
\text { Maksimum }\end{array}$ \\
\hline Tinggi badan & $150 \mathrm{~cm}$ & $180 \mathrm{~cm}$ \\
Berat badan & $41,9 \mathrm{~kg}$ & $93,45 \mathrm{~kg}$ \\
Tinggi & $36 \mathrm{~cm}$ & $50 \mathrm{~cm}$ \\
popliteal & & \\
Tinggi lutut & $42 \mathrm{~cm}$ & $62 \mathrm{~cm}$ \\
Panjang kaki & $21 \mathrm{~cm}$ & $29 \mathrm{~cm}$ \\
Lebar kaki & $7 \mathrm{~cm}$ & $12 \mathrm{~cm}$ \\
\hline
\end{tabular}

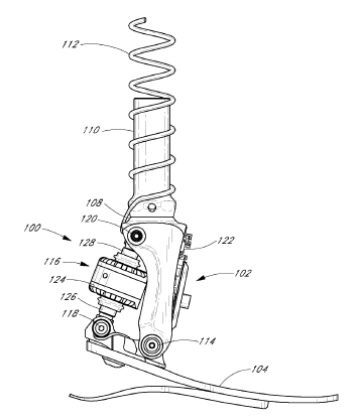

Gambar 1. Foot [3].
Kemampuan foot untuk memberikan dorongan ke depan ketika berjalan sangat diperlukan oleh pengguna prostesis bawah lutut. Pada penelitian yang telah dilaksanakan sebelumya telah dibahas mengenai prostesis yang akan memberikan dorongan ke depan. Dorongan ke depan ini diakibatkan karena adanya cekungan yang terletak pada bagian tumit yang terlihat pada gambar 2. Selain jenis foot tersebut pada bagian shank terdapat sebuah pengikat yang langsung mengikat pada bagian amputasi [4].

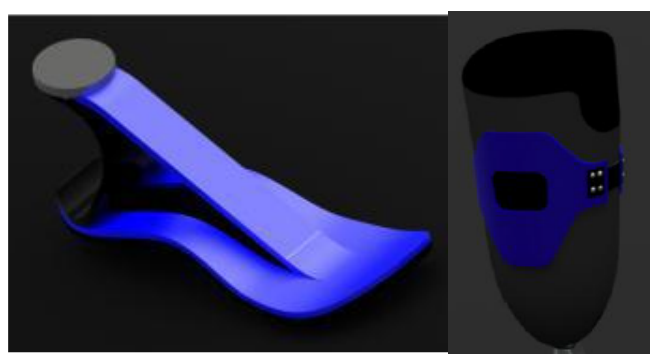

Gambar 2. Foot dan socket [4]

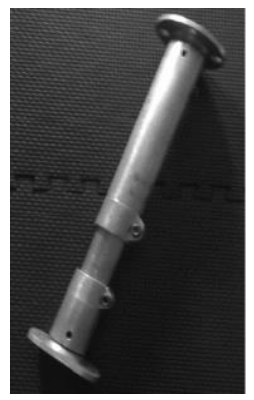

Gambar 3. Shank [5].

Pengatur ketinggian pada shank sangat diperlukan jika ingin dibuat prostesis yang dapat menyesuaikan ketinggian seseorang. Gambar 3 menunjukkan shank yang memiliki mekanisme pergerakan untuk bergeser ke atas dan ke bawah sedangkan penggunaan pengunci hanya menggunakan baut pada bagian bawah shank yang akan mencekam bagian poros pada shank. Selain itu penggunaan material yang berrongga akan memperringan massa prostesis yang dibuat [5].

Jenis shank pada gambar 4 dikembangkan agar bagian shank tidak mengalami puntiran. Pemberian pitch yang memanjang ke bawah dapat mengurangi pergerakan memutar dari bagian shank. Namun jenis pengunci yang digunakan hanya mampu mencekam agar tidak terjadi putaran pada bagian shank akan 
tetapi masih memungkinkan terjadinya pergeseran kearah vertikal [6].

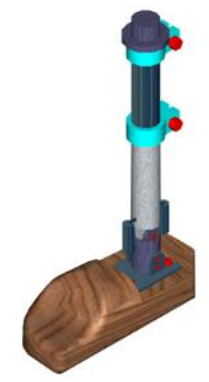

Gambar 4. Shank [6]

\section{Metode}

Pembuatan prostesis bawah lutut akan melalui beberapa tahapan yang tersusun secara berurutan sesuai dengan alur penelitian yang telah ditentukan. Gambar 5 menunjukkan alur penelitian yang akan dilaksanakan dalam pembuatan prostesis bawah lutut.

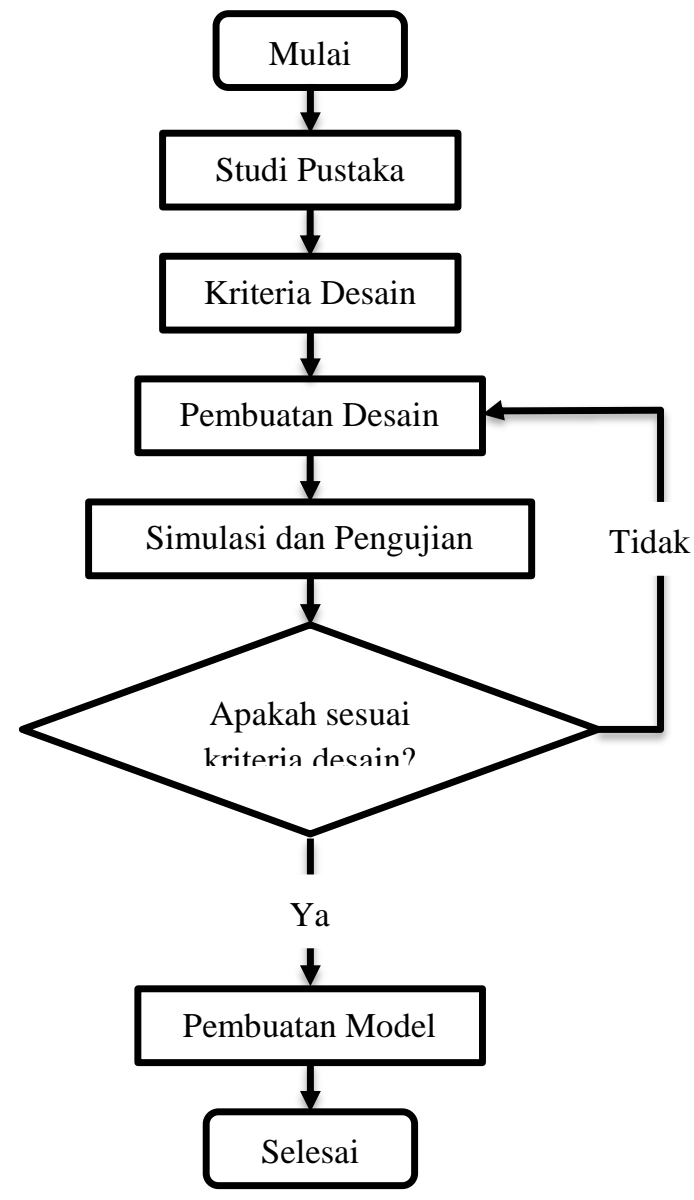

Gambar 1. Alur Penelitian

Pemilihan kriteria desain didasarkan pada permasalahan pada prostesis yang telah ada sebelumnya. Tabel 2 merupakan daftar kriteria desain yang dijadikan sebagai tujuan akhir dalam pembuatan prostesis bawah lutut ini.
Tabel 2. Kriteria Desain

\begin{tabular}{|c|c|}
\hline Kriteria & Deskripsi \\
\hline Kuat & $\begin{array}{l}\text { Mampu menahan berat badan hingga } \\
100 \mathrm{~kg} \text { [7] }\end{array}$ \\
\hline $\begin{array}{l}\text { Kemampuan } \\
\text { setting }\end{array}$ & $\begin{array}{l}\text { Prostesis dapat digunakan pria } \\
\text { maupun wanita dengan ketentuan }\end{array}$ \\
\hline ketinggian & tinggi badan antara $150 \mathrm{~cm}-180 \mathrm{~cm}$ \\
\hline Ringan & $\begin{array}{l}\text { Memiliki massa lebih ringan dari pada } \\
\text { kaki sesungguhnya yaitu kurang dari } \\
2,3883 \mathrm{~kg}[8]\end{array}$ \\
\hline $\begin{array}{l}\text { Jenis } \\
\text { Prostesis }\end{array}$ & $\begin{array}{l}\text { Prostesis merupakan prostesis dengan } \\
\text { jenis endoskeletal yang bentuknya } \\
\text { tidak menyerupai kaki sesungguhnya }\end{array}$ \\
\hline Kenyamanan & $\begin{array}{l}\text { Mudah dalam kembali ke posisi } \\
\text { mendatar ketika digunakan dalam } \\
\text { kondisi berjalan maupun berdiri }\end{array}$ \\
\hline $\begin{array}{l}\text { Umur tak } \\
\text { hingga }\end{array}$ & $\begin{array}{l}\text { Memiliki safety factor empat kali dari } \\
\text { beban maksimal yang diterima. }\end{array}$ \\
\hline
\end{tabular}

Tahapan ketiga adalah pembuatan desain prostesis bawah lutut menggunakan software CAD. Pembuatan desain prostesis perlu memperhatikan massa bagian tubuh yang mengalami amputasi. Desain prostesis diharuskan memiliki massa lebih rendah dari bagian kaki yang diamputasi. Menurut Tayyari tahun 1997 berat bagian kaki dibawah lutut memiliki berat sebesar 5,7 \% dari berat manusia[8]. Dari nilai tersebut maka dapat dihitung berat maksimal prostesis senilai :

$$
\begin{aligned}
\text { Massa maksimal } & =5,7 \% \times \text { massa orang Indonesia } \\
& =5,7 \% \times 41,9 \mathrm{~kg} \\
& =2,3883 \mathrm{~kg}
\end{aligned}
$$

Berdasarkan perhitungan di atas maka berat prostesis harus berada di bawah $2,3883 \mathrm{~kg}$, sehingga tidak akan membebani penggunanya. Massa terendah orang Indonesia diambil dari data yang telah diperoleh yaitu seberat 41,9 kg, diambil nilai paling rendah karena jika diambil berat badan paling tinggi akan membuat pengguna yang memiliki berat badan penggunanya maka prostesis yang dibuat tidak dapat digunakan oleh keseluruhan orang Indonesia.

Pembuatan desain prostesis ini merupakan pengembangan dari desain-desain yang telah ada. Terdapat perbaikan pada bagian foot, shank, socket, dan sistem suspensi sehingga dapat menyesuaikan antropometri orang Indonesia dengan ketinggian antara 150 sampai $180 \mathrm{~cm}$. Pengembangan yang paling menonjol terdapat pada bagian shank. Pada bagian ini terdapat bagian berupa pitch yang bertujuan untuk mengatur ketinggian prostesis. Konsep awal hanya dibuat dalam bentuk sketsa, hal ini bertujuan agar desain selanjutnya sesuai dengan kriteria desain yang telah ditentukan sebelumnya. Selain itu diharapkan prostesis memiliki desain yang tidak jauh berbeda dari konsep awal yang telah ditentukan. Dari 
pembuatan sketsa prostesis bawah lutut yang telah dilaksanakan dapat diperoleh sketsa desain seperti gambar 6.

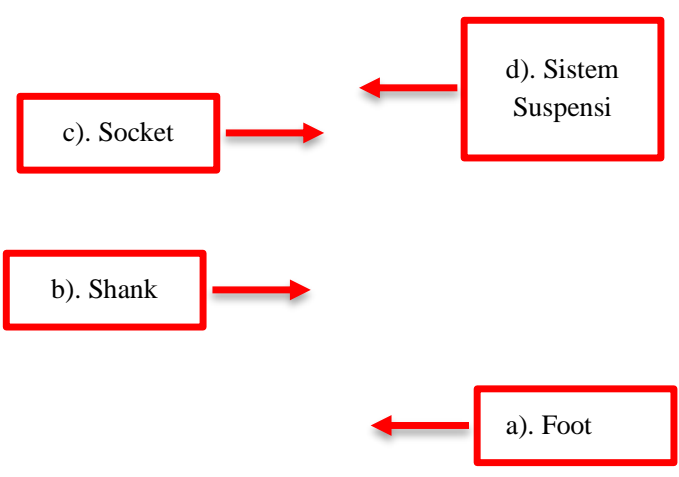

Gambar 6. Sketsa Prostesis Bawah Lutut

Berdasarkan sketsa prostesis pada gambar 6 dapat diuraikan mengenai konsep awal dari prostesis yang akan dibuat. Agar konsep awal dari desain dapat dipaparkan secara rinci maka pembahasan dilaksanakan dalam setiap komponen. Bagian foot memiliki bentuk yang meyerupai alas kaki secara menampang. Bagian ini terdiri dari dua buah bagian yang dihubungkan menggunakan mur dan baut seperti yang terlihat pada gambar 6 bagian a. Bagian pertama merupakan bagian utama yang akan menyangga prostesis. Pada bagian tumit dibuat melengkung agar memiliki dapat memiliki efek pegas ketika digunakan berjalan. Sementara itu pada bagian kedua terdapat sebuah penyangga yang akan memperkuat prostesis ketika dalam kondisi menumpu dan akan memeberikan dorongan ketika akan melangkah. Foot harus memiliki sifat elastis oleh karena itu kedua bagian foot menggunakan material berupa carbonfiber. Desain foot dikembangkan dari bagian foot yang diambil dari Google Patent yang terlihat pada gambar 1 .

Shank harus memiliki kekuatan yang tinggi sehingga ketika mengalami tekanan dari atas akan tetap kuat dan tidak patah., akan tetapi bagian ini harus menggunakan material yang ringan. Penggunaan alumuniaum pejal merupakan pilihan yang tepat karena material ini memiliki kekuatan yang tinggi dengan massa yang ringan. Selain penggunaan material yang kuat bagian shank ini dibuat agar dapat diatur sehingga dapat menyesuaikan rentang ketinggian dari orang Indonesia. Oleh karena itu pada bagian shank terdapat pitch seperti gambar 6 bagian $b$ yang akan memudahkan pengguanan, hal ini merupakan pengambangan dari desain diambil dari gambar 3 .

Sketsa socket pada gambar 6 bagian c dikembangkan dari desain pada gambar 2, dibuat dengan bagian belakang lebih rendah dibandingkan pada bagian samping maupun depan. Hal ini bertujuan agar bagian popliteal masih dapat menekuk selain itu diharapkan socket mampu menyesuaikan bagian yang diamputasi sehingga dapat digunakan dengan ukuran yang berbeda-beda. Untuk mengurangi kondisi lembab pada bagian amputasi maka bagian luar socket dibuat memiliki lubang sehingga akan terjadi sirkulasi udara pada bagian socket. Bahan utama dari socket ini berupa karet silikon dan pada bagian dalam terdapat dakron yang akan langsung bersentuhan dengan kulit penggunanya.

Sistem suspensi terdiri dari tiga buah pengikat, ketiga buah pengikat tersebut hanya difungsikan untuk mengikat bagian belakang dari sisa amputasi. Tiga bagian ini terbuat dari bahan yang elastis sehingga tidak akan menggores kulit saat digunakan. Sistem suspensi ini memiliki tujuan agar socket tidak mudah lepas dari bagian amputasi, selain itu diharapkan agar ukuran sistem suspensi dapat menyesuaikan ukuran bagian amputasi. Jenis sistem suspensi yang akan digunakan akan terlihat pada gambar 6 bagian $\mathrm{d}$.

Setelah keseluruhan desain selesai dibuat maka tahapan selanjutnya Simulasi dan pengujian. Pengujian dilakukan pada 3 buah kondisi ketika seseorang berjalan, yaitu ketika posisi heal loading, midfoot loadong dan forefoot loading. Pengujian ini didasarkan pada ISO 10328 yang menerapkan beberapa sudut dan tumpuan yang berbeda pada pengujian protesis bawah lutut. Untuk lebih jelasnya dapat terlihat pada gambar 7, akan terlihat posisi pembebanan dan daerah yang akan menjadi tumpuan.

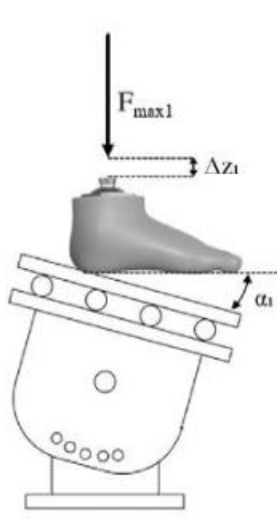

a). Heal loading

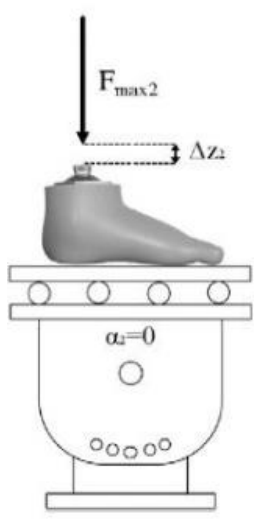

b). Midfoot loading

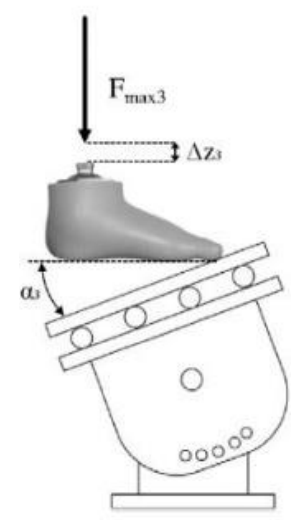

c). Forefoot loading
Gambar 7. Kondisi pengujian

Ketika keadaan heal loading seperti terlihat pada gambar 7a bagian foot hanya bertumpu pada bagian belakang yaitu bagian tumit. Hal tersebut mengakibatkan telapak kaki dan bidang pijakkan akan membentuk sudut $15^{\circ}$. Sedangkan pada kondisi midfoot loading mengakibatkan kondisi telapak kaki menumpu pada dua bagian telapak kaki. Gambar 7b menunjukkan kondisi pijakan yang mendatar dan membentuk sudut $0^{\circ}$ dengan telapak kaki. Sementara itu pada pengujian dengan kondisi forefoot loading memiliki letak titik tumpu berada di ujung bagian depan dari telapak kaki. Posisi tersebut seperti gambar 7c menunjukkan telapak kaki akan membentuk sudut $20^{\circ}$ dengan bidang pijakan dengan titik tumpu berada 
pada bagian jari kaki. Beban yang diberikan pada ketiga kondisi pengujian berasal dari bagian atas atau bagian socket sebesar $100 \mathrm{~kg}$ dengan safty factor 4 .

Tahapan terakhir berupa pembuatan model prostesis bawah lutut dengan menggunakan 2 metode pembuatan yaitu 3D Printing dan proses permesinan. Komponen yang dibuat menggunakan 3D Printing berupa bagian foot, penyambung foot dengan shank, mur penguat dan socket. Bagian shank dibuat dengan menngunakan mesin bubut dikarenakan material yang digunakan berupa alumunium dan memiliki pitch melingkar yang menyerupai ulir. Setelah keseluruhan komponen dari prostesis ini selesai dibuat baik itu melalui proses 3D print maupun proses permesinan maka selanjutnya dilakukan proses perakitan. Perakitan model prostesis bawah lutut dihubungkan menggunakan mur dan baut.

\section{Hasil dan Pembahasan}

Setelah dilakukan pemodelan menggunakan software CAD diperoleh desain yang menyesuaikan kriteria desain dan menyesuaikan jenis barang yang ada dipasaran. Dari perancangan prostesis bawah lutut yang telah dilaksanakan dapat diperoleh desain akhir seperti pada gambar 8. Terdapat beberapa perubahan jika dibandingkan dengan konsep awal, perubahan yang mencolok terlihat pada bagian shank dengan foot dan sistem suspensi.

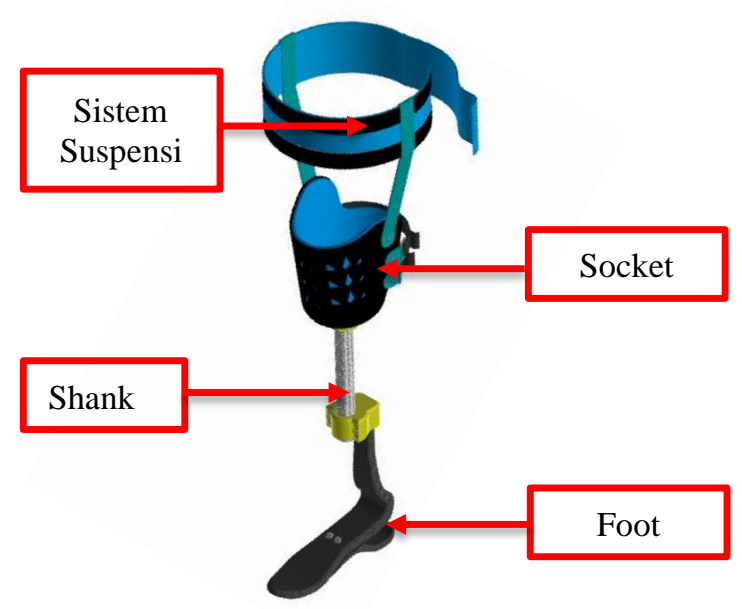

Gambar 8. Hasil Perancangan Prostesis

Berdasarkan hasil perancangan yang telah dibuat seperti yang terlihat pada gambar 8 telah memiliki massa dibawah massa rata-rata terrendah yaitu seberat $1,74 \mathrm{~kg}$. Selanjutnya untuk memperjelas hasil desain secara lebih mendalam maka akan didibahas menjadi masing-masing komponen dari setiap bagian prostesis.

Desain foot yang terlihat pada gambar 8 memiliki beberapa perbaikan sehingga dapat digunakan oleh beberapa orang dengan kondisi antropometri yang hampir sama. Hal tersebut dipengaruhi karena penggunaan ukuran kaki terkecil dalam pembuatan bagian foot.

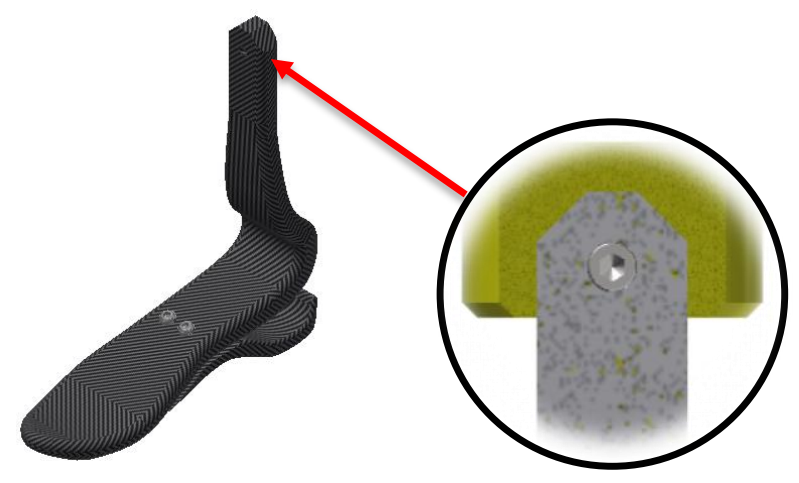

Gambar 9. Desain Foot

Telapak kaki hanya menggunakan ukuran panjang 21 $\mathrm{cm}$ dan lebar $7 \mathrm{~cm}$ agar orang yang memiliki ukuran kaki lebih besar tetap dapat mengguankannya. Penggunaan material berupa carbonfiber akan memberikan gaya lenting kedepan ketika digunakan. Gaya lenting ini akan mempermudah pergerakan prostesis ketika digunakan untuk berjalan. Selain itu gaya lenting ini diakibatkan karena bagian ankle memiliki bentuk menekuk dan bagian penyangga sendiri memiliki jarak untuk memberi tuang tekukan pada tumit sehingga dorongan akan menjadi lebih besar. Selain akan memberikan gaya dorong ke depan, bagian tumit juga akan meredam pergerakan bagian tumit sehingga ketika digunakan prostesis tidak akan terasa kaku.

Bagian atas foot dibuat memanjang agar dapat memberikan ruang pergeseran pada bagian shank. Penghubung antar bagian menggunakan baut dan mur sehingga akan memudahkan jika akan dilakukan proses bongkar pasang.

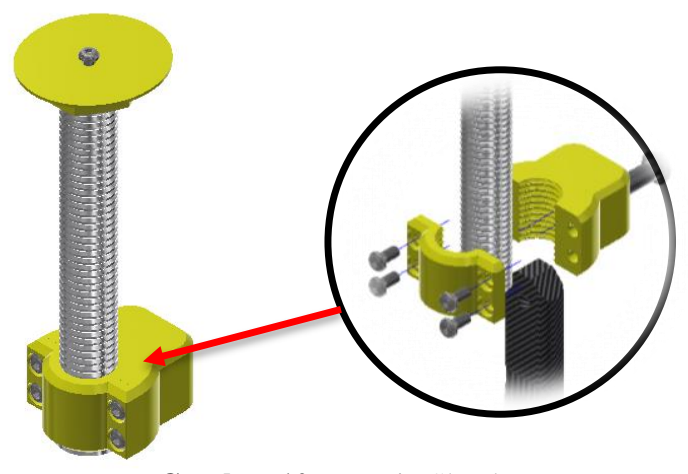

Gambar 10. Desain Shank

Shank memiliki kemampuan pergeseran setinggi 14 $\mathrm{cm}$, hal ini menyesuaikan pergeseran tinggi popliteal dari orang Indonesia. Kemampuan pergeseran ini dapat menyesuaikan dengan kondisi tinggi badan penggunanya. Terdapat pitch yang akan menjadi pengunci pergerakan keatas maupun kebawah pada bagian shank. Masing-masing pitch memiliki ketinggian setinggi $3,5 \mathrm{~mm}$, oleh harena itu mengakibatkan terdapat 40 tingkatan pergeseran pada 
bagian shank. Dapat terlihat pada gambar 10 bagian penghubung shank dengan foot dan sekaligus digunakan sebagai pengunci shank agar tidak bergerak. Bagian atas penyambung dibuat tertutup sehingga bagian foot terpasang dengan baik dan dapat memperkuat bagian baut akibat tegangan yang terjadi.

Penggunaan material berupa alumunium pejal pada bagian shank akan membuat rangka prostesis menjadi lebih ringan dan kuat. Selain itu penggunaan shank dengan tipe endoskeletal akan membuat prostesis menjadi lebih stabil dan seimbang ketika digunakan. Sementara itu pada bagian bagian penyambung dan bagian mur penguat terbuat dari bahan ABS yang memiliki massa yang ringan. Mur penguat pada bagian atas dibuat melebar dan menyesuaikan luas darah pada bagian bawah socket, hal ini disebabkan karena bagian ini berfungsi sebagai penyangga bagian socket agar tidak menekuk kebagian bawah saat dipasang pada bagian amputasi.

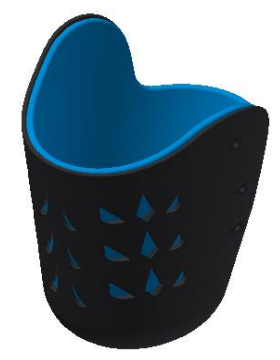

Gambar 11. Desain Socket

Gambar 11 menunjukkan desain socket yang telah dibuat menggunakan software CAD. Socket ini dapat digunakan oleh penderita disabilitas dengan diameter sisam amputasi antara $90 \mathrm{~mm}$ hingga $150 \mathrm{~mm}$. Sedangkan tinggi dari bagian amputasi yang dapat masuk pada bagian socket setinggi 130 sampai 160 mm. Penggunaan material pada bagian luar socket akan membuat socket menjadi lebih elastis, sementara pada bagian dalam akan dilapisi bahan berupa dakron untuk mengurangi gesekan langsung pada bagian amputasi selain itu dalam dapat menjadi lebih nyaman ketika digunakan. Bagian belakang socket dibuat menjadi lebih rendah jika dibandingkan dengan bagian depan dan samping dikarenakan bagian ini dibuat agar mampu menyesuaikan diameter bagian amputasi. Selain itu akan dugunakan sebagai peletakan titik popliteal sehingga dapat menekuk dengan baik.

Desain sistem suspensi pada gambar 12 terlihat berbeda dengan kosep awal pembuatan desain dikarenakan ditambahkan pengikat pada bagian paha. Pengikat pada bagian paha ini dapat diatur untuk diameter $11 \mathrm{~cm}$ hingga $22 \mathrm{~cm}$. Selain itu pengikat pada bagian belakang akan mengikat bagian amputasi secara langsung. Jenis sistem suspensi ini didesain sesuai dengan barang yang ada di pasaran.

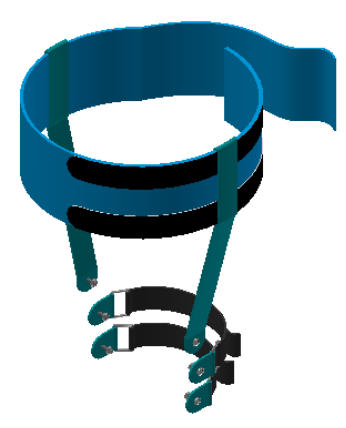

Gambar 12. Desain Sistem Suspensi

Setelah keseluruhan desain dibuat kemudian dilakukan pengujian terhadap prostesis bawah lutut sesuai dengan ISO 10328. Simulasi ini menggunakan software CAE yang diharapkan dapat mewakili pengujian secara langsung

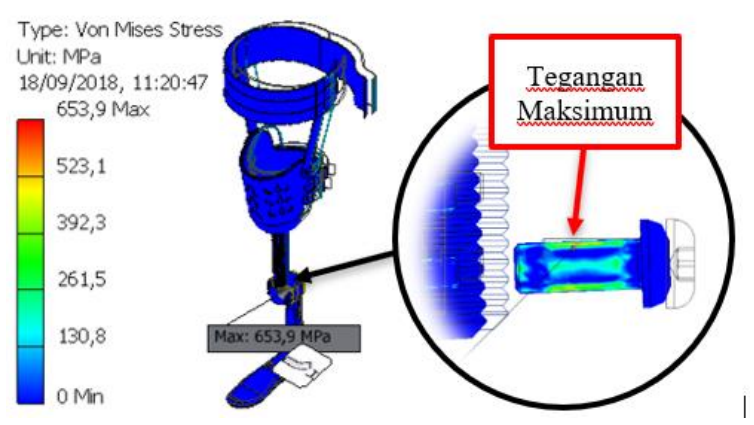

Gambar 13. Hasil Pengujian Prostesis Kondisi Heal Loading

Berdasarkan hasil pengujian dengan kondisi heal loading pada gambar 10 diperoleh hasil bahwa prostesis mampu menahan beban yang diterima kaki ketika berjalan. Terlihat pada gambar 10 bahwa prostesis berwarna biru yang menandakan prostesis mampu menahan beban yang diberikan. Kondisi pada bagian atas dari prostesis akan bergerak ke depan dikeranakan bagian tumpuan berada di ujung belakang. Sementara itu tegangan maksimum yang terjadi senilai 653,9 Mpa pada baut bagian penghubung shank dengan foot. Penumpukan tegangan terjadi pada sudut dalam bagian baut dengan luasan yang kecil. Kondisi ini masih dapat ditahan oleh baut karena pada bagian sekitarnya tegangan yang terjadi relatif kecil.

Terlihat pada gambar 14 bahwa pengujian dengan kondisi midfoot loading akan memberikan dampak berupa dorongan ke depan yang mengakibatkan prostesis cenderung condong ke depan. Pada kondisi ini beban maksimum terjadi pada bagian baut pada penyambung shank dengan foot. Tegangan maksimum yang terjadi memiliki besar senilali 458,9 Mpa. Disini terjadi penumpukan distribusi tegangan yang memiliki daerah kecil pada bagian baut, hal ini masih dapat ditahan baut karena pada bagian penghubung shank dengan foot terdapat bagian penumpu yang berada pada bagian atas baut. 


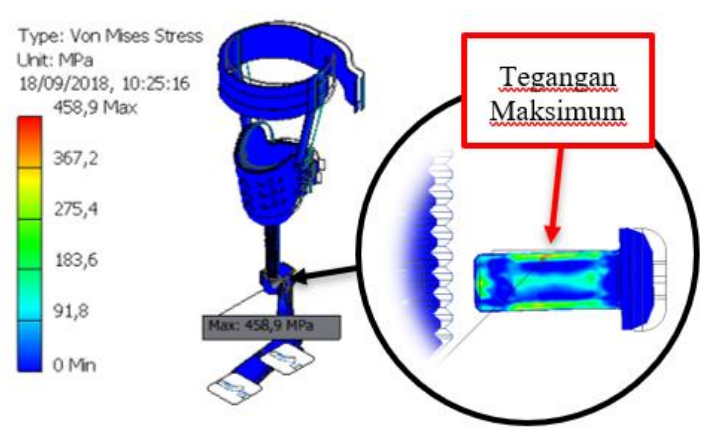

Gambar 14. Hasil Pengujian Prostesis Kondisi Midfoot Loading

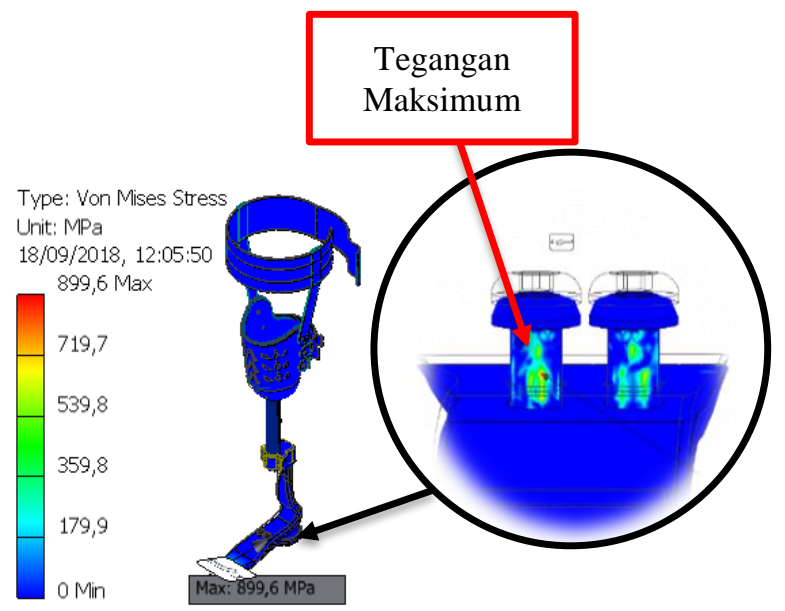

Gambar 15. Hasil Pengujian Prostesis Kondisi Forefoot Loading

Tegangan maksimum pada kondisi forefoot loading ketika diberi baban $100 \mathrm{~kg}$ yaitu 899,6 MPa yang terjadi pada baut dibagian foot. Seperti gambar 15 menunjukkan tingginya tegangan yang terjadi karena titik tumpuan berada di ujung depan dari prostesis. Hal ini mengakibatkan perbedaan arah kemiringan prostesis yang condong ke belakang. Pergerakan prostesis yang cenderung condong ke belakang ini sangat berguna karena ketika digunakan ketika terjadi pergerakan sehingga akan memberikan dorongan kedepan ketika berjalan.

Pengujian melalui simulasi menunjukan bahwa tegangan terkecil berada pada kondisi midfoot loading sedangkan tegangan tertinggi berada pada kondisi forefoot loading. Tegangan terjadi bada baut pengunci, sehingga dibutuhkan baut yang mampu menahan tegangan minimal sebesar 899,6 MPa. Spesifikasi material menunjukan bahwa material yang memiliki tegangan luluh diatas kebutuhan adalah baja austenitik 301 seperempat keras yang memiliki tegangan luluh sebesar $931 \mathrm{Mpa}$.
Tabel 3. Spesifikasi Material Baja Tahan Karat

\begin{tabular}{|c|c|c|c|c|c|c|}
\hline \multicolumn{2}{|c|}{ Penandaan bahan } & \multirow[b]{2}{*}{ Kondisi } & \multicolumn{2}{|c|}{ Kekuatan tarik } & \multicolumn{2}{|c|}{ Tegangan luluh } \\
\hline No. AISI & UNS & & (ksi) & $(\mathrm{MPa})$ & (ksi) & (MPa) \\
\hline \multicolumn{7}{|c|}{ Baja Austenitik } \\
\hline \multirow[t]{5}{*}{201} & S20100 & Dianil & 115 & 793 & 55 & 379 \\
\hline & & $1 / 4$ keras & 125 & 862 & 75 & 517 \\
\hline & & $1 / 2$ keras & 150 & 1030 & 110 & 758 \\
\hline & & 3 keras & 175 & 1210 & 135 & 931 \\
\hline & & Keras penuh & 185 & 1280 & 140 & 966 \\
\hline \multirow[t]{5}{*}{301} & S30100 & Dianil & 110 & 758 & 40 & 276 \\
\hline & & $1 / 4$ keras & 125 & 862 & 75 & 517 \\
\hline & & $1 / 2$ keras & 150 & 1030 & 110 & 758 \\
\hline & & \% kerns & 175 & 1210 & 135 & 931 \\
\hline & & Keras penuh & 185 & 1280 & 140 & 966 \\
\hline \multirow[t]{3}{*}{304} & S30400 & Dianil & 85 & 586 & 35 & 241 \\
\hline & & Dianil & 95 & 655 & 45 & 310 \\
\hline & & Dianil & 80 & 552 & 30 & 207 \\
\hline
\end{tabular}

\section{Kesimpulan}

Inovasi desain yang dilakukan menunjukan prostesis dapat digunakan oleh orang Indonesia dengan rentang tinggi badan antara $150 \mathrm{~cm}$ sampai $180 \mathrm{~cm}$. Sedangkan hasil simulasi dari desain menunjukan bahwa prostesis tersebut mampu menahan beban hingga $100 \mathrm{~kg}$ dengan safety factor 4 .

\section{Daftar Pustaka}

[1] A. Diono, F. A. Prasetyo, dan D. Budijanto, "Situasi Penyandang Disabiltas," Kemtrian Kesehatan RI, 2014.

[2] R. Arinbjörn Viggo Clausen dan H. Magnus Oddsson, "TRANSFEMORAL PROSTHETIC SYSTEMS AND METHODS FOR OPERATING THE SAME," US 8,057,550 B2.

[3] Arinbjörn Viggo Clausen, R., \& Magnus Oddsson, H. (n.d.). US 8,057,550 B2. 1: United States Paten.

[4] R. A. F. Fauziah dan A. B. Sriwarno, "Pengembangan Desain Kaki Prostetik yang Berbasis Low-Cost untuk Industri Kecil Kaki Palsu Di Indonesia," Program Studi Sarjana Desain Produk, Fakultas Seni Rupa dan Desain (FSRD) ITB, 2014.

[5] A. Prakoso, "Perancangan dan Pembuatan Prototype shank Prostheses Kaki Bagian Bawah Lutut," Program Studi Aeronautika STT Adisutjipto, 2016.

[6] Chuan, T. K., \& Kumar, M. (2010). Anthropometry of Sungapuren and Indonesian Population. International Journal of Industrial E, 40.

[7] D. Jumeno dan A. W. Adlis, "Desain Prosthesis Endoskeletal Bawah Lutut Untuk Penyandang Cacat,” Jurusan Teknik Industri, Fakultas Teknik Universitas Andalas, 2010.

[8] Tayyari, \& Smith. (1997). Occupational Egronomics Principles and Applications. New York: Chapment \& Hall. 